\title{
THE OPINION OF EMPLOYEES AND CHILDREN LIVING IN FOSTER CARE HOMES ABOUT ROMANIAN NATIONAL CLEAN AIR LEGISLATION ON TOBACCO SMOKING
}

\author{
NIMRÓD TUBÁK ${ }^{1}$, IOZSEF LORAND FERENCZ ${ }^{2}$, VALENTIN NĂDĂŞAN ${ }^{3}$, ENIKŐ NEMES \\ NAGY ${ }^{4}$, LÓRÁND KOCSIS ${ }^{5}$, ZOLTÁN ÁBRÁM ${ }^{6}$ \\ 1,2,3,4 “George Emil Palade” University of Medicine, Pharmacy, Science, and Technology of Tîrgu Mureş, ${ }^{5}$ Student "George Emil Palade” University \\ of Medicine, Pharmacy, Science, and Technology of Tîrgu Mureş
}

Keywords: foster care home, smoking, children, anti-tobacco legislation
Abstract: This study aims to assess the awareness and opinions of employees and children living in foster care homes about the Romanian Clean Air Legislation. The assessment was performed six months after the implementation of the antitobacco legislation (Romanian Law no.15/2016), in three Romanian counties (Alba, Mures, and Covasna) including 178 employees and 368 children from 59 foster care homes. Data were collected using an anonymous paper and pencil questionnaire. Descriptive statistics and chi-square test were used for data analysis (significant difference if $p<$ 0.05). Almost one third of the employees and children were smokers from the forest care homes. Nearly, all the employees and most of the children were aware of the legislation, most of them have also noticed some kind of measures taken by foster care homes against smoking. As claimed by smokers, almost two-thirds of them smoked like they used to do before the legislation, more than a quarter stated that they decreased the number of daily smoked cigarettes and nearly a quarter intended to quit smoking in the future. A half year after the implementation of the legislation most of the employees and children living in foster care homes admitted that they knew about the change and it affected their smoking habits. Most of them have also observed some kind of measures taken against smoking. Despite these measures there were still smokers in the foster care homes, so there would be a need for more campaigns against smoking in the future.

\section{INTRODUCTION}

According to WHO, more than 7 million people die because of tobacco-related diseases annually.(1) If this trend goes on by 2030 this will be about 8 million deaths per year.(2) In the United States of America, smoking kills about 480.000 people per year, which means one out of five deaths is caused by smoking.(3) On average, smoking shortens life by 10 years.(4)

On the report of a large study published in 2017 in which there were involved 41 countries from all over the world the prevalence of smoking was $27.3 \%$; on the earth, there was an estimated 1.1 billion people who smoke.(5) Over $80 \%$ of smokers come from developing countries, most of them have a low income, and bad life conditions.(6-8) In the disadvantaged population from the European Union, the number of deaths is three times higher.(9)

The WHO data shows that the prevalence of tobacco smoking among persons older than 15 years is $28.7 \%$ in Europe and $30.0 \%$ in Romania.(1) Based on the results of the Eurobarometer survey, the daily smokers have a rate of $24.0 \%$ in Europe and nearly $20.0 \%$ in Romania from the general population.(12)

The most Europeans start smoking between the age of 15 and 18 years $(53.0 \%$ according to a report from 2015) (13), Marcon A. et al. achieved almost similar results with $47.0 \%$ in 2015.(14) According to the Health Behaviour in School-aged Children (HBSC) study (2014), the $14.0 \%$ of 15 -year-old

\section{Romanian boys smoke daily and $20 \%$ occasionally.(15)}

The Eurostat data shows that there is a difference between the daily smoker rates by age groups almost in every European country (including Romania), with a lower rate for the 15-24 age group, compared to age groups older than 25 years. In Romania, there is a $15.0 \%$ daily smoker rate for the $15-24$ age group and a $32.0 \%-43.9 \%$ for the age groups between 25 64.(16) Romanian statistics show that $25.9 \%$ of foster care residents between the ages of 12 and 18 declare themselves as smokers.(10) Schmidt et al. in 2016 found that the smoking prevalence among the foster care parents is $30-45 \%$ and they have a direct impact on these foster care children regarding their smoking habits.(11)

In Romania, employees and children who live and work in foster care units are a part of the disadvantaged category and belong to the National Authority for the Protection of the Rights of the Child and Adoption in Romania. According to 2016 data, there were 57.000 cases, of which 20.156 children lived in foster care residencies.(11) Romania, on 2016 March $17^{\text {th }}$, implemented the anti-tobacco legislation (Romanian Law no. 15/2016), which amended the Law nr. 349/2002. The legislation's main objective was to ban smoking in closed areas at workplaces and public spaces.

${ }^{2}$ Corresponding author: Iozsef Lorand Ferencz, Str. Gh. Marinescu, Nr. 38, Tîrgu-Mureş, România, E-mail: lorandferencz@yahoo.com, lorand.ferencz@umfst.ro, Phone: +40751 439262

Article received on 15.06.2019 and accepted for publication on 10.08.2020 


\section{PUBLIC HEALTH AND MANAGEMENT}

care children and employees about the anti-tobacco legislation in three Transylvanian counties.

\section{MATERIALS AND METHODS}

The assessment took place six months after the implementation of the antitobacco legislation (Romanian Law no. 15/2016), in three Transylvanian counties (Alba, Mures, Covasna) including 59 foster care homes.

The questions addressed the following items: sociodemographics including employee position, age, gender distribution (male, female), tobacco use including current smoking status (daily, occasionally, never, past smoker), antitobacco legislation including awareness regarding smoking legislation, prohibition of smoking in various places (yes/no), new measures implemented after the enactment of the legislation (yes/no) and smokers behaviour including reduced number of cigarettes smoked (yes, no), do not influenced (yes/no), started using e-cigarettes (yes/no).

A total of 546 people responded to the questionnaire. We excluded 55 children who were younger than 12 years old and older than 18 years old. The responses of 178 employees (48 males, 130 females) and 313 children (151 males, 162 females) were included in the analysis. The mean age of the children was $14.6 \pm 1.72$, while most of the employees were in the 40-49 age group. Our research team included specialists like doctors, medical assistants, psychiatrists. We conducted a survey, with an anonymous paper and pencil questionnaire, which contained a total of 25 questions.

\section{Statistical analysi}

Nominal variables were displayed as relative frequencies (\%) and the comparison between groups (employees vs. children) was performed using Pearson Chi-squared test or Fisher's Exact test. A p value of $<0.05$ was considered statistically significant. The statistical analysis was performed using the IBM SPSS Statistic 25 (IBM Corporation, USA) program.

\section{RESULTS}

According to our results, the prevalence of smoking was $29.8 \%$. The smoking status was the same for employees as well as children, $20.0 \%$ smoked daily, $9.8 \%$ occasionally and $4.1 \%$ were past smokers $(\mathrm{p}=0.533)$. There was also no difference in the age group $(p=0.11)$, gender $(p=0.16)$ or the employee's position $(\mathrm{p}=0.204)$ referring to the smoking status. Nearly all the employees and three-quarters of the children were aware of the legislation $(97.7 \%$ vs. $76.1 \%, p<0.001), 76.5 \%$ of employees and $60.4 \%$ of children $(p<0.001)$ have also noticed some steps taken by foster care homes against smoking. A percentage of 64.8 of the kids have noticed these regulations similarly in schools.

As table no. 1 shows, more employees were aware ( $>90 \%$ in all cases) then children $(77.2 \%-80.9 \%)$ about the places where smoking was banned by law $(\mathrm{p}<0.001$ in all cases).

A quarter of smokers stated that they decreased the number of daily smoked cigarettes, a higher proportion of adults $(44.9 \%$ vs. $19.8 \%, \mathrm{p}<0.001)$ and besides them nearly a quarter $(24.2 \%)$ intends to quit smoking in the near future, with no difference in proportion between groups $(\mathrm{p}=0.553)$.

According to the results, a few people (employees and children) have started using E-cigarettes $(6.6 \%)$ in closed areas where smoking is not allowed, in the same proportion in both group $(\mathrm{p}=0.774)$.

Furthermore, more than $70.0 \%$ of smokers claimed, that the legislation has not influenced their behaviour, they smoke as before, with no significant difference between employees and children $(\mathrm{p}=0.537)$
Table no. 1. The answer for the following question „In which of the following places is smoking banned by the law?"

\begin{tabular}{|c|c|c|c|}
\hline \multirow[b]{2}{*}{$\begin{array}{l}\text { Different spaces, places } \\
\text { and institutions }\end{array}$} & \multicolumn{2}{|c|}{ Yes answers } & \multirow[b]{2}{*}{ p value } \\
\hline & $\begin{array}{c}\text { Employe } \\
\text { es } \\
(n=178)\end{array}$ & $\begin{array}{l}\text { Children } \\
(\mathrm{n}=\mathbf{3 1 3})\end{array}$ & \\
\hline Restaurants (indoors) & $95.9 \%$ & $80.9 \%$ & $<0.001$ \\
\hline Child-care institutions & $95.9 \%$ & $80.4 \%$ & $<0.001$ \\
\hline Schools & $95.3 \%$ & $78.8 \%$ & $<0.001$ \\
\hline Playgrounds & $94.6 \%$ & $77.2 \%$ & $<0.001$ \\
\hline Hospitals & $95.2 \%$ & $79.9 \%$ & $<0.001$ \\
\hline Churches & $95.2 \%$ & $80.3 \%$ & $<0.001$ \\
\hline $\begin{array}{ll}\text { Indoor grocery } & \text { or } \\
\text { convenience stores } & \end{array}$ & $95.2 \%$ & $78 \%$ & $<0.001$ \\
\hline
\end{tabular}

According the results, $23.2 \%$ claimed that they smoke at least 10 meters from the foster care home, $4.9 \%$ outside, around the house or in the yard and $0.7 \%$ smoke inside, but only in specific rooms.

After 6 months from the implementation of the legislation, $10.6 \%$ of the adults and $4.2 \%$ of the children admitted that they have seen smokers in the foster care homes.

\section{DISCUSSIONS}

Our study shows that the prevalence of smoking among employees (adults) and children from foster care homes in Romania is $29.8 \%$, which compared to the previous results reported by WHO (1) is nearly the same for Romania $30.0 \%$, older than 15 years) and it is slightly higher than the European average ( $28.7 \%$, older than 15 years).

We found the same smoking rate among children and adults, contrary to previous studies.(13-15) As our results shows the employees who smoke daily have the same rate as the general population from the Eurobarometer survey report 2017 (12) (nearly $20.0 \%$ in both studies). Based on our results the proportion of children smoking daily $(20.0 \%$, age $12-18)$ shows a higher value than the data of Romanian children at year 15 $(14.0 \%)$ in the HBSC study (15) and the proportion of people between age 15-24 (15.0\%) in the Eurostat study.(16) Lorand FI. et al. in 2016 showed that $25.9 \%$ of foster care residents between the ages of 12 and 18 declare themselves as smokers (10), summing the daily and the occasionally smokers from our study we found a higher smoking rate $(29.8 \%)$. Smoking appears to be more prevalent among children living in foster care homes.

According to most research the tobacco control policies and the anti-smoking legislations decrease the cigarette consumption. $(17,18)$ The results of Chaloupka and Wechsler published in 1997 showed that the smoking restrictions in the US have a negative effect on smoking rate.(19) Adda and Cornaglia found that smoking bans in restaurants and bars decrease the cigarette consumption.(20) Our result shows that the implementation of the anti-tobacco legislation in Romania has an impact on the frequency of smoking and the number of people who intends to quit smoking. A quarter of smokers stated that they decreased the number of daily smoked cigarettes (in a higher proportion the adults), which was similar to the results of Bhat N. et al.(17) in which $27.7 \%$ of smokers reduced the number of cigarettes they smoke after the introduction of antismoking legislation in India. Furthermore, our results showed that a quarter of the employees and children from the Romanian foster care units intends to quit smoking after the implementation of the smoke-free legislation, which is a lower value than the results from Ireland $(36.4 \%)$ or in England (47.3\%).(21) A few people have started using E-cigarettes in closed areas where smoking is not allowed, which goes beyond the topic of this paper.

It is noteworthy that six months after the implementation of the antitobacco legislation the employees and 


\section{PUBLIC HEALTH AND MANAGEMENT}

children from the foster care units are well informed. Nearly all the employees and three-quarter of the children were aware of the legislation. The employees are more informed about the smoke free places, 9 out of 10 adults recognized the forbidden places, while only 8 out of 10 children recognized the same thing. It is also remarkable that most of the smokers have noticed some kind of measures taken by foster care homes against smoking as required by law, these kinds of measures according to Foley K. et al. had an effect on reducing smoking in the foster care units.(11) Despite all these a three-quarter of smokers claimed that the legislation has not influenced their behaviour, they smoke as before and only a quarter of both employees and children claimed that they smoke at least 10 meters from the foster care home. Moreover, there are still persons who smoke around the house or in the yard or even inside the building.

\section{CONCLUSIONS}

A half year after the implementation of the antitobacco legislation most of the employees and children from the Romanian foster care units admitted that they know about the modifications. A quarter of them stated that it has an impact on the frequency of smoking or the intention to quit smoking. Most of them have also observed some kind of measures taken against smoking. Despite these measures, 6 months after the implementation of the legislation there are still smokers in the foster care homes, so there would be a need for more campaigns against smoking in the future.

\section{REFERENCES}

1. WHO report on the global tobacco epidemic 2017. World Health Organization. https://www.who.int/tobacco. Published July 26, 2019. Accessed January 3, 2019.

2. WHO report on the global tobacco epidemic 2011. World Health Organization. https://www.who.int/tobacco. Published February 7, 2017. Accessed February 19, 2018.

3. National Center for Chronic Disease Prevention and Health Promotion (US) Office on Smoking and Health. The Health Consequences of Smoking-50 Years of Progress: A Report of the Surgeon General. Atlanta (GA): Centers for Disease Control and Prevention (US); 2014.

4. Jha P, Ramasundarahettige C, Landsman V. 21st-Century Hazards of Smoking and Benefits of Cessation in the United States. Journal of Vascular Surgery. 2013;57(5):1448.

5. Stubbs B, Veronese N, Vancampfort D, et al. Perceived stress and smoking across 41 countries: A global perspective across Europe, Africa, Asia and the Americas. Scientific Reports. 2017;7(1).

6. Najem B, Houssière A, Pathak A, et al. Acute cardiovascular and sympathetic effects of nicotine replacement therapy. Hypertension 2006; 47:1162.

7. Hiscock R, Dobbie F, Bauld L. Smoking Cessation and Socioeconomic Status: An Update of Existing Evidence from a National Evaluation of English Stop Smoking Services. BioMed Research International. 2015;2015:1-10.

8. Galobardes B. Indicators of socioeconomic position (part 1). Journal of Epidemiology \& Community Health. 2006;60(1):7-12.

9. Kunst AE, Giskes K, Mackenbach JP. Socioeconomic inequalities in smoking in the European Union:applying an equity lens to tobacco control policies. Erasmus MC. Rotterdam, Netherlands; 2004.

10. Lorand FI, Zoltan A, Lorand S, Peter B, Foley KL. Tobacco use among children in Romanian foster care homes. Eur J Public Health. 2016 Oct;26(5):822-826.

11. Foley K, Ferencz L, Meghea C, et al. Home- and Car-
Based Rules in Foster Care Settings to Reduce Exposure to Secondhand Smoke: Before and after Romanian National Clean Air Legislation. International Journal of Environmental Research and Public Health. 2018;15(8):1631.

12. Special Eurobarometer 458: Attitudes of Europeans towards tobacco and electronic cigarettes - European Union Open Data Portal. Datasets. https://data.europa.eu. Accessed June 2, 2020.

13. Special Eurobarometer 458: Attitudes of Europeans towards tobacco and electronic cigarettes. Dataset. https://ec.europa.eu. Accessed June 3, 2020.

14. Marcon A, Pesce G, Calciano L, et al. Trends in smoking initiation in Europe over 40 years: A retrospective cohort study. Plos One. 2018;13(8).

15. Health Behaviour in School-aged Children (HBSC). World Health Organization. http://www.euro.who.int. Published June 3, 2020. Accessed June 3, 2020.

16. Statistical office of the European Union. Tabacco consumption statistics. Luxembourg:Eurostat. https://ec.europa.eu/eurostat. Accessed June 3, 2020.

17. Bhat N, Oza S, Reddy JJ, Mitra R, Rahul P, Singh S. Effect of Anti-Smoking Legislation in Public Places. Addict Health. 2015;7(1-2):87-91.

18. Palali A, Ours JCV. The impact of tobacco control policies on smoking initiation in eleven European countries. The European Journal of Health Economics. 2019;20(9):12871301.

19. Chaloupka FJ, Wechsler H. Price, tobacco control policies and smoking among young adults. Journal of Health Economics. 1997;16(3):359-373.

20. Adda J, Cornaglia F. The Effect of Bans and Taxes on Passive Smoking. American Economic Journal: Applied Economics. 2010;2(1):1-32.

21. Nagelhout GE, Vries HD, Boudreau C, et al. Comparative impact of smoke-free legislation on smoking cessation in three European countries. The European Journal of Public Health. 2012;22(Suppl 1):4-9.

22. e campaigns against smoking in the future.Geraud $G$, Spierings EL, Keywood C. Tolerability and safety of frovatriptan with short- and long-term use for treatment of migraine and in comparison with sumatriptan. Headache. 2002;42 Suppl 2:S93-9. 